\title{
Características de Carcaça de Bezerros de Rebanhos Leiteiros Desmamados Precocemente e Alimentados com Diferentes Dietas Líquidas ${ }^{1}$
}

\author{
Antonio Bento Mancio ${ }^{2}$, Rafael Henrique de Tonissi e Buschinelli de Goes ${ }^{3}$, Álvaro Luiz \\ Marinho Castro ${ }^{4}$, Paulo Roberto Cecon ${ }^{5}$, Alonso Thiago Silvestre da Silva ${ }^{6}$
}

\begin{abstract}
RESUMO - Avaliaram-se o rendimento de carcaça e o desenvolvimento dos órgãos e vísceras de 40 bezerros mestiços F1 Holandês x Gir alimentados com diferentes dietas líquidas, à base de leite integral ou colostro fermentado, associados ou não com óleo de soja (45 mL), com ou sem a aplicação do promotor de crescimento Zeranol. Cada animal recebeu dieta composta por ração concentrada (23\% de proteína bruta), feno de capim-tifton à vontade e três litros de leite ou colostro fermentado por dia. Os animais foram abatidos com peso médio de $57,38 \mathrm{~kg}$ e aproximadamente 60 dias de idade. Não houve efeito das dietas fornecidas aos animais sobre o peso dos órgãos e dos componentes não-integrantes da carcaça. Entretanto, os bezerros tratados com leite e Zeranol apresentaram maiores pesos de carne industrial. A área de olho de lombo dos bezerros não foi influenciada pela associação dos diferentes tipos de dietas com o Zeranol, apresentando um valor médio de $15,27 \mathrm{~cm}^{2}$. O colostro fermentado sem a adição de Zeranol e apresentou pesos, para rúmen-retículo, intestino delgado e mesentério, de 954, 2.076 e 619 g, respectivamente. A presença do óleo de soja na dieta líquida elevou a porcentagem de gordura interna dos bezerros. A utilização do Zeranol acarretou comprimento de carcaça 5\% superior nos animais tratados com leite e 5,5\% inferior nos animais tratados com colostro, enquanto o uso do colostro fermentado sem Zeranol resultou em carcaças 5\% mais pesadas que o de leite integral sem Zeranol. Desempenho (peso de carcaça quente e fria) semelhante aos dos animais tratados com leite e promotor de crescimento foi obtido com o tratamento Zeranol + colostro fermentado. Animais tratados com leite apresentaram maiores proporções de osso e de gordura na carcaça.
\end{abstract}

Palavras-chave: biometria, colostro fermentado, leite integral, óleo de soja, Zeranol

\section{Effect of Feeding Different Liquid Diets on Carcass Characteristics of Early Weaned Dairy Calves}

\begin{abstract}
Carcass yield and growth of organs and innards of 40 crossbreed F1 Holstein X Gir calves fed different liquid diets (whole milk or fermented colostrum-based diets), supplemented or not with soy oil $(45 \mathrm{~mL})$ and with or without growth promoter Zeranol were evaluated. The animals were daily fed a diet with concentrate ( $23 \%$ crude protein), Tifton hay ad libitum and 3 L of milk or fermented colostrum. The animals were slaughtered at average weight of $57.38 \mathrm{~kg}$ and 60 days old. No effect of feeding different liquid diets on the organs weight and non integrate carcass components was detected. However, calves fed milk and Zeranol showed heavier industrial meat weight. No effect of feeding liquid diets with Zeranol on Longissimus dorsi area was observed, with an average value of $15.27 \mathrm{~cm}^{2}$. Animals fed fermented colostrum without Zeranol exhibited respective weights of rumen-reticulum, small intestine and mesentery of 954, 2,076 and $619 \mathrm{~g}$. Calves fed diet supplemented with with soy oil had higher percentage of internal fat. Carcass length increased by $5.0 \%$ in animals fed milk with Zeranol and decreased by 5.5\% in animals fed colostrum with Zeranol. Animals fed fermented colostrum without Zeranol showed carcass 5.0\% heavier than those fed whole milk without Zeranol. Performance (hot and cold carcass weight) of animals fed whole milk with Zeranol was similar to those fed fermented colostrum with Zeranol. Animals fed milk showed greater bone and fat proportions in the carcass.
\end{abstract}

Key Words: development, whole milk, fermented colostrum, soy oil, Zeranol

\section{Introdução}

A produção de carne a partir de bezerros de rebanhos leiteiros baseia-se na incorporação desses animais no processo produtivo, como alternativa de maior eficiência das propriedades produtoras de leite. Com o propósito de se otimizar as variáveis bióticas nos sistemas de produção, são utilizadas estratégias visando ao máximo desenvolvimento dos animais, principalmente na primeira fase de vida.

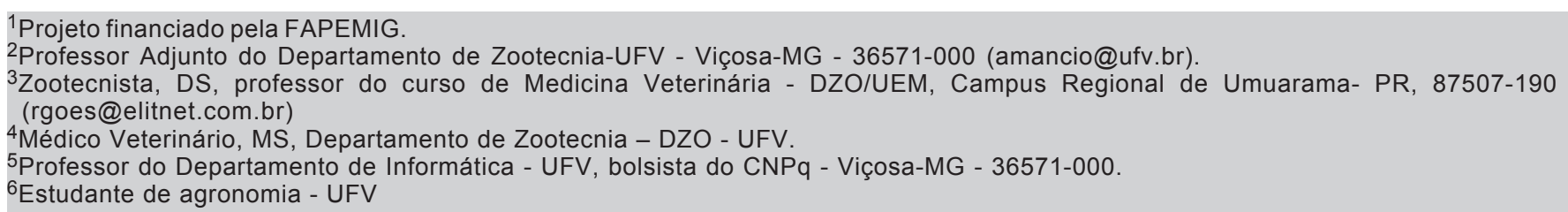


O crescimento animal consiste em uma série de mudanças que ocorrem desde o momento da concepção até a maturidade e envolvem aumento do tamanho corporal e alterações na capacidade funcional de diversos órgãos (Grant \& Helferich, 1991). Na fase inicial de crescimento, a somatrotopina é o hormônio responsável por promover processos anabólicos para o crescimento dos músculo e ossos e os desenvolvimentos físico e funcional das vísceras.

Ao nascer, os bezerros são considerados préruminantes e apresentam seu trato digestivo anatomicamente semelhante ao de não-ruminantes. Por isso, a dieta líquida constitui-se a base para obtenção de nutrientes, uma vez que o rúmen, retículo e omaso se encontram em fase inicial de desenvolvimento. O fornecimento de concentrado nesta fase favorece o desenvolvimento funcional dos compartimentos do trato gastrintestinal, em razão da produção de ácidos graxos voláteis, responsáveis pelo desenvolvimento das papilas ruminais. Outro fator importante é que nesta fase os animais apresentam melhores taxas de aproveitamento do concentrado, de modo que seu fornecimento contribui para a obtenção de maiores taxas de crescimento do animal (Anderson et al., 1981; Quigley et al., 1985; Lucci, 1989).

O rendimento de carcaça em muitos casos não fornece uma estimativa adequada do rendimento de carne aproveitável, uma vez que o tecido adiposo tem o efeito de diluir a proporção de músculos e órgãos e grande parte desse tecido é eliminada, reduzindo a fração aproveitável (Jorge, 1993).

Visando tornar o sistema de classificação menos subjetivo, algumas mensurações são utilizadas, entre elas a área de olho de lombo, o comprimento de carcaça, que expressa, em porcentagem de peso vazio, a capacidade do animal de produzir carne e a relação peso vivo do animal/comprimento de carcaça (Hankins \& Howe, 1946). O comprimento de carcaça está correlacionado ao peso da carcaça e dos cortes de maiores valores econômicos.

O estudo quantitativo das partes não-integrantes da carcaça é importante, pois estas tendem a variar de acordo com o grupo genético e exercem influência direta sobre o rendimento de carcaça, a exigência de manutenção e o ganho de peso (Berg \& Butterfield, 1979).

Neste trabalho, objetivou-se avaliar o rendimento de carcaças e o desenvolvimento de órgãos e vísceras de bezerros mestiços Holandês x Gir, alimentados com diferentes dietas líquidas, à base de leite integral ou colostro fermentado, associados com Zeranol e/ou óleo de soja.

\section{Material e Métodos}

O experimento foi conduzido nas dependências do Setor de Bovinocultura de Leite do Departamento de Zootecnia da Universidade Federal de Viçosa-MG, no período de abril a agosto de 1997.

Foram utilizados 40 bezerros Holandês x Gir, com peso médio inicial de $36 \mathrm{~kg}$ provenientes da EMBRAPA Gado de Leite, Coronel Pacheco-MG, e do Setor de Bovinocultura do DZO/UFV, Viçosa-MG, alojados em baias individuais $(1,10 \times 1,70 \mathrm{~m})$, dotadas de piso ripado de madeira e comedouros individuais, para concentrado e volumoso.

Ao completarem 15 dias de idade, iniciou-se o período experimental. À medida que chegavam ao local eram identificados, numerados, pesados, desverminados e receberam uma dose do complexo vitamínico ADE injetável.

Cada animal recebeu diariamente, no período da tarde, três litros de cada dieta avaliada. A ração concentrada inicial contendo $23 \%$ de proteína bruta foi fornecida em quantidades crescente até o limite de $1,5 \mathrm{~kg} /$ dia e o feno de capim-tifton (Cynodon spp) foi disponibilizado à vontade.

O leite integral foi utilizado a fresco, após a ordenha da tarde. $\mathrm{O}$ colostro proveniente de vários animais, foi armazenado em tambores de plástico de 60 litros e homogeneizados diariamente, sendo fermentado ao natural por sete dias e utilizado em até 28 dias.

As dietas líquidas avaliadas foram: leite integral (L); leite integral com óleo de soja (LO); leite integral e zeranol (LZ); leite integral com óleo de soja e zeranol (LOZ); colostro fermentado (CF); colostro fermentado com óleo de soja (CFO); colostro fermentado e zeranol (CFZ); colostro fermentado com óleo de soja e zeranol (CFOZ).

Para os animais alimentados com LO, LOZ, CFO e CFOZ, foram adicionados à dieta $45 \mathrm{~mL}$ de óleo degomado de soja e 2,5 mL de emulsificante à base de lecitina de soja. Nas dietas contendo colostro fermentado, foram acrescentados $25 \mathrm{~g}$ de bicarbonato de sódio, como agente tamponante.

O implante do pélete com Zeranol (36 mg) foi aplicado via subcutânea, na orelha, nos animais que recebiam $\mathrm{LZ}$, LOZ, CFZ e CFOZ, ao completarem 15 dias de idade.

As análises químicas foram feitas no laboratório de Nutrição Animal do Departamento de Zootecnia da Universidade Federal de Viçosa, para determinação dos teores de matéria seca (MS), proteína bruta 
(PB), cinzas (CZ), extrato etéreo (EE), fibra em detergente neutro $(\mathrm{FDN})$ e fibra em detergente ácido (FDA) das dietas líquidas e sólidas, segundo metodologia descrita por Silva \& Queiroz (2002). A gordura total foi calculada por intermédio de um butirômetro. O teor de carboidratos totais (CHOT) foi estimado por $\mathrm{CHOT}(\%)=100-\mathrm{PB} \%-\mathrm{EE} \%-\mathrm{MM} \%$ e os carboidratos não-estruturais (CNE), pela diferença entre CHOT e FDN (Sniffen et al., 1992). As composições das diferentes dietas e dos alimentos são apresentadas nas Tabelas 1 e 2 .

Após o término do período experimental, os animais apresentaram peso médio de $57,38 \mathrm{~kg}$; foram submetidos a um jejum de 16 horas e abatidos por meio de concusconcusão cerebral e secção da veia jugular. A carcaça foi dividida em duas metades e, em seguida, foi pesada. Também foram computados os pesos referentes a patas, cabeça, couro, rúmenretículo, omaso, abomaso, intestino delgado, intestino grosso, gordura interna, fígado, coração, rins, baço, pulmões, língua, sangue, mesentério, carne industrial, cauda, peso do conjunto traquéia e esôfago e aparelho reprodutor.

$\mathrm{O}$ trato gastrintestinal foi pesado cheio e vazio, para a determinação do peso de corpo vazio (PCVZ). As meia-carcaças foram levadas à câmara fria, onde permaneceram por 18 horas, a $-5^{\circ} \mathrm{C}$, para a determinação do peso da carcaça fria (PCF). Na meiacarcaça esquerda, foi realizada a medida do comprimento de carcaça e retirada uma seção entre a $9^{\mathrm{a}} \mathrm{e}$ $11^{\mathrm{a}}$ costelas, para se determinar a proporção de ossos, músculos e tecido adiposo, segundo Hankins \& Howe (1946), em que: $\%$ músculo $=16,08+0,80 X ; \%$ tecido adiposo $=3,54+0,80 \mathrm{X}$ e $\%$ ossos $=5,52+0,57 \mathrm{X} ; \mathrm{em}$ que $X$ representa a porção do componente na seção retirada entre a $9^{\mathrm{a}}$ e a $11^{\mathrm{a}}$ costelas (seção $\mathrm{HH}$ ).

Ainda na meia-carcaça esquerda, foi determinada a área de olho de lombo do músculo Longissimus dorsi, na altura da $12^{\mathrm{a}}$ costela. Na meia-carcaça direita resfriada, foi calculado o rendimento de cortes básicos (dianteiro: acém e ponta de agulha completos; traseiros: alcatra e coxão).

O delineamento estatístico utilizado foi o inteiramente casualizado em esquema fatorial $2^{3}$, conforme o modelo descrito:

$$
\begin{gathered}
\mathrm{Y}_{\mathrm{ijkl}}=\mathrm{m}+\mathrm{A}_{\mathrm{i}}+\underset{\mathrm{O}}{\mathrm{O}_{\mathrm{j}}+\mathrm{P}_{\mathrm{k}}+\mathrm{AO}_{\mathrm{ij}}+\mathrm{AP}_{\mathrm{ik}}+\mathrm{OP}_{\mathrm{jk}}}+ \\
\mathrm{AOP}_{(\mathrm{ijk}) 1}
\end{gathered}
$$

em que $\mu=$ constante geral, $\mathrm{A}_{\mathrm{i}}=$ efeito referente ao alimento líquido $\mathrm{i}\left(\mathrm{i}=1\right.$ e 2); $\mathrm{O}_{\mathrm{j}}=$ efeito referente à adição de óleo de soja $(j=1$ e 2$) ; P_{k}=$ efeito referente à aplicação do promotor de crescimento $(\mathrm{k}=1 \mathrm{e} 2)$; $\mathrm{AO}_{\mathrm{ij}}, \mathrm{AP}_{\mathrm{ik}}, \mathrm{OP}_{\mathrm{jk}}, \mathrm{AOP}_{\mathrm{ijk}}=$ interações entre os efeitos principais; e e ${ }_{(\mathrm{ijk}) 1}=$ erro- padrão, associado à cada observação, pressuposto NID $\sim\left(0, \sigma^{2}\right)$.

\section{Resultados e Discussão}

Os maiores teores de proteína bruta (PB) para o leite e colostro fermentado acrescidos de óleo de soja (Tabela 1) provavelmente decorreram da inclusão de lecitina de soja, que possui o radical trimetil amina (colina) no terceiro grupamento ligante, que elevou o nível de nitrogênio encontrado nas soluções analisadas.

Em virtude das características físico-químicas do óleo de soja e da lecitina de soja, não se obteve perfeita homogeneização desses componentes com o colostro fermentado. A lecitina de soja apresenta um efeito homogeneizante melhor quando adicionada na forma sólida (Campos \& Silva, 1986); neste trabalho, foi administrada na forma líquida, o que pode ter interferido no teor de gordura total das dietas à base de colostro fermentado (Tabela 1).

As dietas não alteraram $(\mathrm{P}>0,05)$ a área de olho de lombo dos bezerros apresentando média de $15,27 \mathrm{~cm}^{2}$. Foram verificadas diferenças para pesos de carcaças quente e fria, no estudo da interação entre dieta líquida e promotor de crescimento (Tabela 3 ).

$\mathrm{O}$ promotor de crescimento Zeranol promoveu maiores pesos de carcaças quente e de carcaça fria

Tabela 1 - Teores de matéria seca (MS), proteína bruta (PB), gordura total (GT) e cinzas (CZ), com base na matéria seca, para as diferentes dietas líquidas

Table 1 - Contents of dry matter (DM), crude protein (CP), total fat (TF) and ash, for different liquid diets, dry

\begin{tabular}{|c|c|c|c|c|}
\hline Dieta líquida & $\mathrm{MS}(\%)$ & $\mathrm{PB}(\%)$ & GT(\%) & $\mathrm{CZ}(\%)$ \\
\hline Liquid diet & $D M(\%)$ & $C P(\%)$ & $T F(\%)$ & Ash (\%) \\
\hline Leite(L) & 10,47 & 27,00 & 29,61 & 6,44 \\
\hline $\operatorname{Milk}(M)$ & & & & \\
\hline $\begin{array}{l}\text { L comóleo(LO) } \\
M \text { with oil }(M O)\end{array}$ & 10,61 & 29,61 & 39,59 & 6,93 \\
\hline $\begin{array}{l}\text { Colostro fermentado }(\mathrm{CF}) \\
\text { Fermented colostrum }(F C)\end{array}$ & 8,94 & 48,83 & 12,30 & 13,24 \\
\hline $\begin{array}{l}\text { CF comóleo }(\mathrm{CFO}) \\
F C \text { with oil }(F C O) \\
\end{array}$ & 9,40 & 49,40 & 13,83 & 11,45 \\
\hline
\end{tabular}
matter basis 
quando associado a dietas contendo leite integral; sua associação ao colostro fermentado resultou em menor peso de carcaça, sugerindo interação negativa entre colostro fermentado e Zeranol.

Os animais tratados apenas com colostro fermentado apresentaram carcaças $5 \%$ mais pesadas que aqueles alimentados apenas com leite integral, que, por sua vez foram superados em $11 \%$ pelos animais tratados com leite e Zeranol. Esta vantagem percentual corrobora os resultados encontrados por Vanderwal et al. (1975), que, estudando o efeito de vários agentes anabólicos sobre o desempenho de vitelos, constataram que o uso de Zeranol proporcionou peso de carcaça fria de $30,5 \mathrm{~kg}$.

O colostro fermentado apresentou resultados satisfatórios acima de $30 \mathrm{~kg}$, promovendo o desenvolvimento dos animais. Segundo Berg \& Butterfield (1979), o peso de carcaça fornece subsídios para a avaliação do efeito da dieta no desempenho de bezerros.

Observou-se que o peso de carcaça fria dos animais tratados com leite e Zeranol foi 3,4\% menor que o peso de carcaça quente. Valores semelhantes $(3,7 \%)$ foram verificados nos animais tratados com colostro fermentado, indicando perda de água no processo de refrigeração da carcaça. O Zeranol é um dos fatores responsáveis pela redução do peso das carcaças durante a refrigeração, em função dos elevados teores de água na massa muscular, o que é esperado, graças à promoção do anabolismo protéico (Hall, 1977). A diminuição de peso chegou a 5\% para a carcaça quente em relação à carcaça fria.

Foi verificado efeito $(\mathrm{P}<0,05)$ da dieta líquida sobre o rendimento de carcaça, em função do peso de corpo vazio, uma vez que os animais alimentados com leite apresentaram rendimento maior $(54,2 \%)$ que aqueles que ingeriram colostro fermentado $(51,7 \%)$. Também foi observada influência da dieta e de Zeranol sobre o comprimento de carcaça (Tabela 4).

Os animais tratados com leite apresentaram rendimento de carcaça $5 \%$ a mais que os grupos alimentados com colostro fermentado. A utilização do promotor de crescimento proporcionou comprimento de

Tabela 2 - Teores de matéria seca (MS), proteína bruta (PB), extrato etéreo (EE), cinzas (CZ), carboidratos totais (CHOT), fibra em detergente neutro (FDN), fibra em detergente ácido (FDA), carboidratos não-estruturais (CNE), com base na matéria seca, para a ração concentrada e o feno utilizados

Table 2 - Contents of dry matter (DM), crude protein (CP), ether extract (EE), ash, total carbohydrates (CHOT), neutral detergent fiber (NDF), acid detergent fiber (ADF) and nonstructural carbohydrates (NSC), for the experimental concentrated diet and hay, dry matter basis

\begin{tabular}{|c|c|c|c|c|c|c|c|c|}
\hline & MS & PB & $\mathrm{EE}$ & $\mathrm{CZ}$ & CHOT & FDN & FDA & $\mathrm{CNE}$ \\
\hline & $D M$ & $C P$ & $E E$ & Ash & CHOT & $N D F$ & $A D F$ & $N S C$ \\
\hline $\begin{array}{l}\text { Ração concentrada } \\
\text { Concentrateration }\end{array}$ & 87,32 & 23,21 & 2,92 & 6,92 & 66,95 & 15,08 & 6,80 & 51,87 \\
\hline $\begin{array}{l}\text { Feno } \\
\text { Hay }\end{array}$ & 91,44 & 10,34 & 1,37 & 8,69 & 79,60 & 78,52 & 35,67 & 1,08 \\
\hline
\end{tabular}

Tabela 3 - Valores médios $(\mathrm{kg})$ para pesos de carcaça quente (PCQ) e de carcaça fria (PCF) entre dieta líquida e zeranol Table 3 - Averages $(\mathrm{kg})$ for hot (WHC) and cold carcass (WCC) weights for the liquid diet with or without zeranol

\begin{tabular}{lcccc}
\hline Dieta líquida & \multicolumn{2}{c}{ PCQ $($ WHC $)$} & \multicolumn{2}{c}{ PCF $($ WCC $)$} \\
\cline { 2 - 5 } Liquid diet & $\begin{array}{c}\text { Sem Zeranol } \\
\text { Without Zeranol }\end{array}$ & $\begin{array}{c}\text { Com Zeranol } \\
\text { With Zeranol }\end{array}$ & $\begin{array}{c}\text { Sem Zeranol } \\
\text { Without Zeranol }\end{array}$ & $\begin{array}{c}\text { Com Zeranol } \\
\text { With Zeranol }\end{array}$ \\
\hline $\begin{array}{l}\text { Leite } \\
\text { Milk }\end{array}$ & $32,60 \mathrm{Aa}$ & $36,12 \mathrm{Aa}$ & $31,27 \mathrm{Aa}$ & $34,90 \mathrm{Aa}$ \\
$\begin{array}{l}\text { Colostro fermentado } \\
\text { Fermented colostrum }\end{array}$ & $34,20 \mathrm{Aa}$ & $30,25 \mathrm{Ab}$ & $32,96 \mathrm{Aa}$ & $29,15 \mathrm{Ab}$ \\
\hline
\end{tabular}

Letras maiúsculas iguais na mesma linha e minúsculas na mesma coluna $(P>0,05)$ não diferem pelo teste $F$

Same capital letters within a row and lower cases in the same column $(P>0.05)$ do not differ by $F$ test. 
carcaça 5\% superior nos animais tratados com leite e $5,5 \%$ inferior nos animais tratados com colostro, não sendo registrado efeito das dietas líquidas, sem aplicação de Zeranol, sobre comprimento de carcaça.

Muller (1980) verificou que o comprimento e o rendimento de carcaça são parâmetros que apresentam alta correlação com a porção aproveitável do tecido muscular dos animais. O estudo destas características permite comparar sistemas alternativos de aleitamento com sistemas tradicionais à base de leite integral.

O colostro fermentado pode ser uma fonte nutricional para bezerros em crescimento tão eficiente quanto o leite integral.

Os valores para as porções de osso, músculo e gordura, obtidos na seção HH, encontram-se na Tabela 5. Houve diferença $(\mathrm{P}<0,05)$ para osso e gordura nos animais tratados com leite e colostro fermentado, mas não foi observado efeito para a proporção de músculo na carcaça, que apresentou média de $66,52 \%$.

Para proporções de osso e de gordura na carcaça de bezerros, verificou-se que o leite foi superior ao colostro fermentado.

A baixa deposição de gordura nos animais tratados com colostro fermentado pode ter decorrido da deficiência energética ocasionada por este alimento (Lucci, 1989; Campos et al., 1986). A correção dos níveis energéticos com óleo degomado de soja foi

Tabela 4 - Comprimento de carcaça (CC) (cm) de bezerros tratados com leite ou colostro fermentado, com ou sem a aplicação de zeranol

Table 4 - Averages for carcass length (CL) (cm) of calves fed milk or fermented colostrum with or without zeranol

\begin{tabular}{lcc}
\hline Dieta líquida & \multicolumn{2}{c}{ Zeranol } \\
Liquid diet & \multicolumn{2}{c}{ Zeranol } \\
\cline { 2 - 3 } & Sem & Com \\
Withoutl & With \\
\hline Leite & $66,40 \mathrm{Aa}$ & $68,30 \mathrm{Aa}$ \\
Milk & & \\
Colostro fermentado & $68,60 \mathrm{Aa}$ & $65,00 \mathrm{Bb}$ \\
Fermented colostrum & &
\end{tabular}

Letras maiúsculas iguais na mesma linha e minúsculas na mesma coluna $(P>0,05)$ não diferem pelo teste de $F$.

Same capital letters within a row and lower cases in the same column $(P>.05)$ do not differ by $F$ test. suficiente para manter a integridade do desenvolvimento orgânico do animal como um todo, porém não foi o bastante para igualar os valores energéticos do leite e promover maiores proporções de gordura na carcaça.

Não foi observada diferença $(\mathrm{P}>0,05)$ para os pesos de baço, coração, fígado, pulmões, rins e língua dos animais nos diferentes tratamentos, com médias de $206 \mathrm{~g}( \pm 42,18), 375 \mathrm{~g}( \pm 18,24), 1151,9 \mathrm{~g}( \pm 21,6)$, $738 \mathrm{~g}( \pm 21,14), 416 \mathrm{~g}( \pm 30,44)$ e $227 \mathrm{~g}( \pm 16,60)$, respectivamente, indicando que os diferentes tratamentos permitiram taxas satisfatórias de desenvolvimento para estes órgãos.

Os rendimentos de carne industrial apresentaram variação, com interação entre a dieta líquida e a aplicação do promotor de crescimento (Tabela 6).

A associação de leite e Zeranol ocasionou maiores pesos de carne industrial (267,90 g); contudo, o promotor de crescimento, associado ao colostro fermentado, não apresentou efeito.

$\mathrm{O}$ peso das vísceras rúmen-retículo, intestino delgado e mesentério dos bezerros foi maior para os animais tratados com colostro fermentado e Zeranol que para os alimentados com leite sem Zeranol (Tabela 7). As variáveis omaso, intestino grosso e conjunto esôfago, traquéia e aparelho reprodutor apresentaram médias de $185 \mathrm{~g}( \pm 18,24), 706 \mathrm{~g}$ $( \pm 21,14)$ e $855 \mathrm{~g}( \pm 27,52)$, respectivamente, sem efeito significativo para o tipo de dieta líquida, com ou sem a aplicação de Zeranol.

Os maiores pesos de rúmen-retículo, para os animais tratados com colostro fermentado deveram-se, provavelmente, ao maior consumo de concentrado destes animais (Mancio et al., 2005). A alimentação inicial é capaz de aumentar o processo de transformação em um órgão funcional (Lucci, 1989). O tamanho do rúmen está relacionado à sua capacidade funcional, portanto, os elevados pesos deste órgão podem demonstrar uma transformação numa estrutura funcional, podendo os animais alimentados com colostro fermentado serem desmamados precocemente.

O peso médio de intestino delgado foi menor nos bezerrros tratados com Zeranol associado ao colostro fermentado, enquanto, nos animais alimentados com colostro fermentado sem Zeranol, o peso foi $15,78 \%$ superior ao daqueles tratados com leite integral. 
Tabela 5 - Valores médios para as proporções de osso e de gordura na carcaça de bezerros alimentados com leite integral ou colostro fermentado

Table 5 - Averages of proportions of bone and fat in the carcass of calves fed whole milk or fermented colostrum

\begin{tabular}{lcc}
\hline $\begin{array}{l}\text { Dieta líquida } \\
\text { Liquid diet }\end{array}$ & $\begin{array}{c}\text { Proporção de osso (\%) } \\
\text { Bone proportion }\end{array}$ & $\begin{array}{c}\text { Proporção de gordura (\%) } \\
\text { Fat proportion }\end{array}$ \\
\hline $\begin{array}{l}\text { Leite } \\
\text { Milk }\end{array}$ & $22,85 \mathrm{~A}$ & $9,74 \mathrm{~A}$ \\
$\begin{array}{l}\text { Colostro fermentado } \\
\text { Fermented colostrum }\end{array}$ & $21,43 \mathrm{~B}$ & $8,32 \mathrm{~B}$ \\
\hline
\end{tabular}

Letras maiúsculas na mesma coluna não diferem entre si $(P>0,05)$, pelo teste $F$.

Capital letters in the same column do not differ $(P>0.05)$ by $F$ test.

Tabela 6 - Valores médios de carne industrial $(\mathrm{g})$ dos bezerros alimentados com leite integral ou colostro fermentado, com ou sem aplicação ou de Zeranol

Table 6 - Averages of industrial meat $(g)$ of calves fed whole milk or fermented colostrum, with or without Zeranol

\begin{tabular}{|c|c|c|}
\hline \multirow[t]{2}{*}{$\begin{array}{l}\text { Dieta líquida } \\
\text { Liquid diet }\end{array}$} & \multicolumn{2}{|c|}{$\begin{array}{l}\text { Zeranol } \\
\text { Zeranol }\end{array}$} \\
\hline & $\begin{array}{c}\text { Sem } \\
\text { Withoutl }\end{array}$ & $\begin{array}{l}\text { Com } \\
\text { With }\end{array}$ \\
\hline $\begin{array}{l}\text { Leite } \\
\text { Milk }\end{array}$ & $225,00 \mathrm{Ba}$ & $267,90 \mathrm{Aa}$ \\
\hline $\begin{array}{l}\text { Colostro fermentado } \\
\text { Fermented colostrum }\end{array}$ & $239,00 \mathrm{Aa}$ & $218,00 \mathrm{Ab}$ \\
\hline
\end{tabular}

Letras maiúsculas iguais na mesma linha e minúsculas na mesma coluna $(P>0,05)$ não diferem pelo teste $F$.

Same capital letters within a row and lower cases in the same column $(P>0.05)$ do not differ by $F$ test.
Constatou-se maior peso do abomaso com a utilização de colostro fermentado sem Zeranol (Tabela 8). Segundo Lucci (1989), as dietas líquidas proporcionam melhor desenvolvimento deste órgão, de modo que o volume cresce proporcionalmente ao ganho de peso.

Modesto (2000) verificou maior relação entre abomaso e rúmen-retículo nos animais alimentados com leite que nos alimentados com colostro fermentado. Com isso, estes animais teriam capacidade de processar alimentos sólidos mais precocemente que aqueles tratados com leite.

Houve efeito das dietas líquidas e do Zeranol sobre os pesos de couro, patas e cauda (Tabela 9). As médias para cabeça e sangue foram de $3,181 \mathrm{~kg}( \pm 15,7) \mathrm{e}$ $2,530 \mathrm{~kg}( \pm 24,29)$, não apresentando efeito significativo.

Tabela 7- Valores médios (g) do rúmen-retículo, intestino delgado e mesentério dos animais dos tratamentos envolvendo dieta líquida e zeranol

Table 7 - Averages $(g)$ of rumen-reticulum, small intestine and mesenterium of animals fed liquid diet with or without Zeranol

\begin{tabular}{|c|c|c|c|c|c|c|}
\hline \multirow[t]{2}{*}{$\begin{array}{l}\text { Dieta líquida } \\
\text { Liquid diet }\end{array}$} & \multicolumn{2}{|c|}{$\begin{array}{l}\text { Rúmen-retículo } \\
\text { Rumen-reticulum }\end{array}$} & \multicolumn{2}{|c|}{$\begin{array}{c}\text { Intestino delgado } \\
\text { Small intestine }\end{array}$} & \multicolumn{2}{|c|}{$\begin{array}{l}\text { Mesentério } \\
\text { Mesenterium }\end{array}$} \\
\hline & $\mathrm{SZ}^{1}(W Z)$ & $\mathrm{CZ}^{2}(W Z)$ & $\mathrm{SZ}(W Z)$ & $\mathrm{CZ}(W Z)$ & $\mathrm{SZ}(W Z)$ & $\mathrm{CZ}(W Z)$ \\
\hline Leite & $639 \mathrm{Bb}$ & $795 \mathrm{Aa}$ & $1793 \mathrm{Aa}$ & $2047 \mathrm{Aa}$ & $600 \mathrm{Aa}$ & $680 \mathrm{Aa}$ \\
\hline $\begin{array}{l}\text { Milk } \\
\text { Colostro fermentado } \\
\text { Fermented colostrum }\end{array}$ & $954 \mathrm{Aa}$ & $785 \mathrm{Ba}$ & $2076 \mathrm{Aa}$ & $1695 \mathrm{Bb}$ & 619Aa & 463Aa \\
\hline
\end{tabular}

Médias seguidas de letras maiúsculas iguais na mesma linha e minúsculas na mesma coluna não diferem entre si pelo teste $\mathrm{F}$ a $1 \%$ de probabilidade.

Averages followed by the same capital letters in the same row and small letters in the same column do not differ by $F$ test, at $1 \%$ of probability.

$1=\mathrm{SZ}=$ Sem Zeranol $=W Z=$ Without Zeranol.

$2=\mathrm{CZ}=$ Com Zeranol $=W Z=$ With Zeranol . 
Tabela 8 - Médias de peso de abomaso $(\mathrm{g})$, em função da dieta líquida, com aplicação ou não de Zeranol Table 8 - Averages of abomasum weight ( $\mathrm{g}$ ), as affected by feeding liquid diet with or without Zeranol

\begin{tabular}{|c|c|c|}
\hline \multirow[t]{2}{*}{$\begin{array}{l}\text { Dieta líquida } \\
\text { Liquid diet }\end{array}$} & \multicolumn{2}{|c|}{$\begin{array}{l}\text { Zeranol } \\
\text { Zeranol }\end{array}$} \\
\hline & $\begin{array}{c}\text { Sem } \\
\text { Withoutl }\end{array}$ & $\begin{array}{l}\text { Com } \\
\text { With }\end{array}$ \\
\hline $\begin{array}{l}\text { Leite } \\
\text { Milk }\end{array}$ & $270 \mathrm{Ab}$ & $278 \mathrm{Aa}$ \\
\hline $\begin{array}{l}\text { Colostro fermentado } \\
\text { Fermented colostrum }\end{array}$ & $319 \mathrm{Aa}$ & $264 \mathrm{Ba}$ \\
\hline
\end{tabular}

Letras maiúsculas iguais na mesma linha e minúsculas na mesma coluna não diferem $(P>0,05)$ pelo teste $F$.

Same capital letters within a row and small letters in the same column do not differ $(P>0.05)$ by $F$ test.
A associação de Zeranol com leite integral proporcionou peso de couro semelhante ao dos animais que receberam colostro fermentado sem a aplicação de Zeranol. O peso da cauda foi maior nos animais alimentados com CFZ, ao passo que o das patas foi maior naqueles do tratamento LZ.

Os resultados obtidos foram inferiores para os tratamentos envolvendo colostro fermentado e Zeranol. Possivelmente, o couro, a cauda e os pés apresentaram as mesmas respostas fisiológicas relacionadas à interação entre os teores protéicos e a eficiência do Zeranol (Hall, 1977), uma vez que estes componentes possuem elementos protéicos.

Tabela 9 - Pesos médios $(\mathrm{kg})$ de couro, cauda, e das patas de bezerros alimentados com dietas líquidas, com ou sem aplicação de Zeranol

Table 9 - Averages $(\mathrm{kg})$ for weights of leather, tail, and feet of calves fed liquid diets with or without Zeranol

\begin{tabular}{lcccccc}
\hline $\begin{array}{l}\text { Dieta líquida } \\
\text { Liquid diet }\end{array}$ & \multicolumn{2}{c}{ Couro } & \multicolumn{2}{c}{ Cauda } & \multicolumn{2}{c}{$\begin{array}{c}\text { Patas } \\
\text { Feeet }\end{array}$} \\
\cline { 2 - 7 } & $\mathrm{SZ}^{1}(W Z)$ & $\mathrm{CZ}^{2}(W Z)$ & $\mathrm{SZ}(W Z)$ & $\mathrm{CZ}(W Z)$ & $\mathrm{SZ}(W Z)$ & $\mathrm{CZ}($ WZ) \\
\hline Leite (Milk) & $4,12 \mathrm{Aa}$ & $4,67 \mathrm{Aa}$ & $1,50 \mathrm{Aa}$ & $1,65 \mathrm{Aa}$ & $1,19 \mathrm{Aa}$ & $1,26 \mathrm{Aa}$ \\
Colostro fermentado & $4,66 \mathrm{Aa}$ & $3,95 \mathrm{Bb}$ & $1,68 \mathrm{Aa}$ & $1,40 \mathrm{Ba}$ & $1,24 \mathrm{Aa}$ & $1,04 \mathrm{Ab}$
\end{tabular}

Fermented colostrum

Letras maiúsculas iguais na mesma linha e minúsculas na mesma coluna não diferem $(P>0,05)$ pelo teste $F$.

Same capital letters in the same row and small letters in the same column do not differ $(P>.05)$ by $F$ test.

$1=\mathrm{SZ}=$ Sem Zeranol $=W Z=$ Without Zeranol

$2=\mathrm{CZ}=$ Com Zeranol $=W Z=$ With Zeranol.

\section{Conclusões}

O promotor de crescimento Zeranol foi eficiente apenas em associação com leite integral, proporcionando o maior rendimento e comprimento de carcaça. A associação de Zeranol com colostro fermentado apresentou interação negativa, interferindo no rendimento de carcaça de bezerros pré-ruminantes.

O colostro fermentado constitui-se em fontenutricional adequada para o crescimento de bezerros pré-ruminantes, podendo ser um substituto para o leite integral.

\section{Literatura Citada}

ANDERSON, K.L.; NAGAJARA, T.G.; MORRIL, J.L. Ruminal metabolic development in calves weaned conventionaly or early. Journal of Dairy Science, v.52, n.2, p.218-231, 1981
BERG, R.T.; BUTTERFIELD, R.M. Nuevos conceptos sobre desarrollo del ganado vacuno. Zaragosa: Acribia, 1979. $297 p$.

CAMPOS, O.F.; LIZIERE, R.S.; RODRIGUES, A.A. et al. Colostro fermentado a temperatura ambiente, sem aditivos, para bezerros leiteiros. Revista da Sociedade Brasileira de Zootecnia, v.15, n.4, p.338-339, 1986.

CAMPOS, O.F.; SILVA, A.G. Fontes alternativas de proteínas no sucedâneo de leite para bezerros. Pesquisa Agropecuária Brasileira, v.10, n.21, p.1089-1099, 1986.

GRANT, A.L.; HELFERICH, W.G. An overview of growth. In: PEARSON, A.M.; DUSTON, T.R. (Eds). Growth regulation in farm animals. London: Elsevier Applied Science, v.7. p.1-15, 1991.

HALL, G.A.B. Zeranol, anabólico para ruminantes; uma revisão. Revista da Sociedade Brasileira de Zootecnia, v.6, n.1, p.60-83, 1977.

HANKINS, O.G.; HOWE, P.E. Estimation of the composition of beef carcass and cuts. Washington: USDA (Technical Bulletin- USDA, 926), 1946. 20p. 
JORGE, A.M. Ganho de peso, conversão alimentar e características de carcaça de bovinos e bubalinos. Viçosa, MG: Universidade Federal de Viçosa, 1993. 97p. Dissertação (Mestrado em Zootecnia) - Universidade Federal de Viçosa, 1993

LUCCI, C.L. Bovinos leiteiros jovens - nutrição, manejo, doenças. São Paulo: Nobel, 1989. 371p.

MANCIO, A.B.; GOES, R.H.T.B.; CASTRO, A.L.M. et al. Colostro fermentado, associado ao óleo de soja e promotor de crescimento, em substituição ao leite, na alimentação de bezerros mestiços leiteiros. Revista Brasileira de Zootecnia, v.34, n.4, p.1314-1319, 2005.

MODESTO, E.C. Avaliação e efeitos de dietas líquidas para bezerros desmamados precocemente e estudo anatômohistológico da mucosa do abomaso. Viçosa, MG: Universidade Federal de Viçosa, 2000. 83p. Dissertação (Mestrado em Zootecnia) - Universidade Federal de Viçosa, 2000.

MULLER, L.D. Normas para avaliação de carcaças e concursos de carcaças de novilhos. Santa Maria: Universidade Federal de Santa Maria, 1980. 31p.

QUIGLEY, J.D.; SCHWAB, C.G.; HYLTON, W.E. Development of rumen function in calves: nature or protein reaching the abomasum. Journal of Dairy Science, v.8, n.3, p.694-702, 1985 .
SILVA, D.J.; QUEIROZ, A.C. Análise de alimentos (Métodos Químicos e Biológicos). Viçosa, MG: Universidade Federal de Viçosa, 2002. 239p.

SNIFFEN, C.J.; O'CONNOR, J.D.; Van SOEST, P.J. et al. A net carbohydrate and protein system for evaluating cattle diets: II-Carbohydrate and protein availability. Journal of Dairy Science, v.70, p.562-577.1992.

VANDERWAL, P.; BERENDE, P.L.M.; SPRIESTMA, J.E. et al. Effect of anabolic agent on nitrogen retention of calves. Journal of Animal Science, v.41, n.3, p.986-991, 1975.

Recebido em: 16/12/03

Aceito em: 13/04/05 